\title{
HOST SPECIFICITY IN COLONY-FOUNDING BY POLYERGUS LUCIDUS QUEENS (HYMENOPTERA: FORMICIDAE)
}

\author{
By Linda Goodlog ${ }^{1}$ and Raymond Sanwald ${ }^{2}$
}

\section{INTRODUCTION}

The pine barrens of eastern Long Island in Suffolk County, New York, provide a unique habitat for the obligatory slave-making species Polyergus lucidus Mayr. Here, four species of Formica, belonging to the pallidefulva species group, are used by Polyergus as slaves, although only one slave species is usually found in a single Polyergus nest. This is in contrast to related facultative slavemakers of the genus Formica belonging to the sanguinea species group, found in the same habitat, whose nests commonly contain two or more species serving as slaves. Choice of a host species can occur both through the colony-founding behavior of queens and through the choice of target nests for slave raids. The parasitic Polyergus queens found colonies either by adoption, where a queen invades the nest of a slave species, killing the resident queen and appropriating workers and brood present (Wheeler, 1910), or by "budding", in which a queen invades or is accepted into a host species nest accompanied by workers from her nest of origin (Marlin, 1968).

This experiment reports the results of a study designed to determine whether the choice of host species by a parasitic queen is influenced by her past experience. It was hypothesized that a newlymated Polyergus queen would choose and/or be chosen by a colony of the same host species found in her nest of origin.

\section{METHOD}

The site for the experiment was a two acre lot in Suffolk County, N.Y., on which vegetation is kept closely cropped and where an unusually high density of colonies of potential slave species of

'Psychology Department, Hunter College, City University of New York, 695 Park Ave., New York, N.Y. 10021

2212 Mt. Vernon Ave., Medford, N.Y. 11763

Manuscript received by the editor April 6, 1985 
Polyergus has been maintained. Also on this site are several artificially implanted in-ground Polyergus colonies that use two of the available slave species present. In addition, one portable colony of Polyergus, encased in a plywood box with a removable cover, was used. This colony was kept indoors except during afternoon hours, when it was occasionally placed in a fixed location on the site to allow raids to occur, and during mating flights, so the activity of the reproductives could be monitored. Only colonies using the slave species $F$. schaufussi or $F$. pallidefulva nitidiventris were used since these are the most common in the area.

In late August, when mating flights of Polyergus were expected to begin, female alates were retrieved and labelled as to their colony of origin. Those from in-ground colonies were recovered in the morning under sun-warmed rocks placed over the nest entrances. Those in the portable colony were either removed from inside the nest or recovered when they first emerged from the nest after it was placed outside. Each was briefly immobilized by cooling, labelled with a streak of enamel paint on her gaster, and immediately returned to her home nest. There were no observable behavioral effects of the labeling process once the subjects were returned to the ambient temperature.

On days when conditions were favorable for mating flights, the in-ground colonies were periodically inspected for activity, the portable colony was placed outside and constantly monitored, and the site was searched for labelled and mated Polyergus dealates on the prowl for appropriate host colonies. Recovered dealates were each placed in a $16 \times 150 \mathrm{~mm}$ test tube containing approximately $4 \mathrm{~cm}$ of water held in place with a cotton plug, and were restrained with an additional cotton plug. They were then transferred to the laboratory and within 24 hours presented with a choice of two host species. In an $21.6 \mathrm{~cm} \times 29.2 \mathrm{~cm}$ plastic box were two potential host "colonies", one of $F$. schaufussi and one of $F$. pallidefulva nitidiventris. Each colony consisted of 20 or 30 pupae, two or three callows, and two adult workers, in $16 \times 150 \mathrm{~mm}$ test tube with $4 \mathrm{~cm}$ of water plugged with cotton. The test tubes were a preferred nesting place and once established inside, the small group always chose to remain there except for foraging, "exploratory" activity, and occasional aggressive encounters with workers of the alternate species or a Polyergus queen. Food of honey-water and Tenebrio larvae were provided. 
Callows were included in the host groups because experience had shown that queens in laboratory "adoptions" experience a high death rate due to attacks by the adult slave-species workers, while callows appear to be more accepting and less hostile. The number of adults chosen was considered the absolute minimum required for an interaction, while the number of callows and pupae, equalized between the two species in each test box, was the result of the number available in laboratory colonies of the appropriate species during the course of the experiment.

Each queen, in her own test tube to avoid dehydration, was placed in a box between the parallel test tubes containing the two potential hosts, and the restraining plug was removed. Checks were made daily to see if an adoption had occurred. An adoption was considered complete when the queen was found living in a test tube with workers and brood, and being tended (groomed, fed, or provided with other frequent, non-hostile contact) by the workers, for at least 24 hours.

\section{Results AND Discussion}

Table I summarizes the labelling, recovery, and survival of Polyergus queens. Recovery of the mated queens was facilitated by the fact that all labelled dealates were found within one meter of the nest of origin and all appeared to be attempting to return to their nest, except for two queens who were recovered from under the rock covering the entrance to the home nest itself.

Overall mortality in the adoption test was $59 \%$, but was disproportionately high for queens from Colony II. Of the 13 surviving queens from colonies containing $F$. schaufussi slaves and the one surviving queen from the nest containing $F$. pallidefulva nitidiventris slaves, all were adopted into "colonies" of the slave species found in their nest of origin (binomial test, $p<.001, n=14$ ). Over $70 \%$ of the adoptions occurred within the first 72 hours. The most prolonged interval preceding a successful adoption was 17 days.

In this experiment, it is not possible to know whether the ultimate residence of the queens was determined by their "choice" or by the selective action of the slave species workers. Clearly queens and potential hosts must be accepting of each other for an adoption to occur. Observations of the interactions between the queens and their potential hosts suggested that the initial response to a queen by 
Table 1. Summary of labelling, recovery, and adoption of Polyergus queens.

COLONY
OF ORIGIN
$\begin{aligned} & \text { Host } \\ & \text { species* }\end{aligned}$
Labelled
Recovered
Laboratory
adoptions
$\begin{aligned} & \text { *FN - Formica pallidelfulva nitidiventris } \\ & \text { FS - Formica schaufussi }\end{aligned}$
adult workers of both slave species present is aggression or with-
drawal. For a queen to succeed in becoming adopted, she must
persist in her attempts to contact the workers and become accepta-
ble over time. Laboratory interactions between individual conspe-
cific slave species workers from different colonies usually result in
the death of one or both workers, and the introduction of an alien
conspecific into a slave species nest always results in the death of the
newcomer. These findings suggest that a queen's association, in her
home nest, with slave species workers of the same species as a poten-
tial host, probably does not give her any useful identifiable odor to
diminish the initial aggression of this host.
The observation of large numbers of dealates returning to their
home nest is consistent with findings of Marlin (1968). In the two
recoveries of dealates found in the nest entrances of their original
nest, queens were being attacked by resident slaves. We excavated a
large colony of Polyergus in late August, 1984, and found five deal-
ate and numerous alate queens. Since polygyny is not characteristic
of Polyergus, and since mating flights had been occurring, we
assumed that at least four of these had recently mated and returned
to the nest. In the laboratory, the colony was divided into five parts.
Each part contained one of the dealate queens and a mixture of
slaves and raiders, and was placed in a plastic petri dish nest within
a plastic arena with a sand floor. Four of the queens were usually


found outside the nest dish, running along the sides of the arena, apparently attempting to escape. Only one queen was consistently found within the nest dish and tended by slaves. She was darker than the others and was assumed to be the founding queen. Other queens, both alate and dealate, were observed being attacked by slaves. All the dealates and most of the alates died within two months. However the corpse of the putative founding queen was retained in the nest dish for several days after death while the bodies of the other four were all found far removed from the nest. These observations suggest that it is unlikely that female reproductives are able to spend their first winter in their home colony.

Two matings of labelled alates from Colony $\mathrm{X}$ were observed. Both occurred within one meter of the nest entrance and took place with the queens clinging to blades of grass. The first occurred with a male from the same colony while the second occurred with a male, from a Polyergus colony using the same slave species, who had been introduced by the experimenters.

The adoption results indicate that at least one constraint exists on the interaction of Polyergus lucidus and potential slave species. The slave species found in a queen's nest of origin appears to determine the host species she will successfully invade, although the exact mechanism through which this occurs is unknown. Jaisson (1975) has demonstrated that callows imprint to brood, of their own or different species, present during a critical period following eclosion. Possibly the queens imprint to the host species they encounter upon eclosing. Other potential constraints to be explored include the possibility that the raiders' choice of species to raid, and a queen's choice of males, may be similarly determined by the slave species in their colony of origin.

\section{ACKNOWLEDGEMENTS}

This research was supported by a grant from the Theodore Roosevelt Memorial Fund of the American Museum of Natural History and NSF grant \#BSN-8402041. We thank Stefan Cover and Howard Topoff for their comments on the original manuscript, and Anton Allen, Steven Siega, Alexander Singleton, and Phillip Yang for their assistance in the field. 


\section{REFERENCES}

JAISSON, P.

1975. L'impregnation dans l'ontogenese des comportements de soins aux cocons chez la jeune Fourmi rousse (Formica polyctena Forsten). Behaviour 52: 1-37.

MarLin, J.C.

1968. Notes on a new method of colony foundation employed by Polyergus lucidus Mayr. Transactions of the Illinois State Academy of Science 61, 207-209.

WHEELER, W.M.

1910. Ants: their structure, development, and behavior. Columbia University Press, New York. 

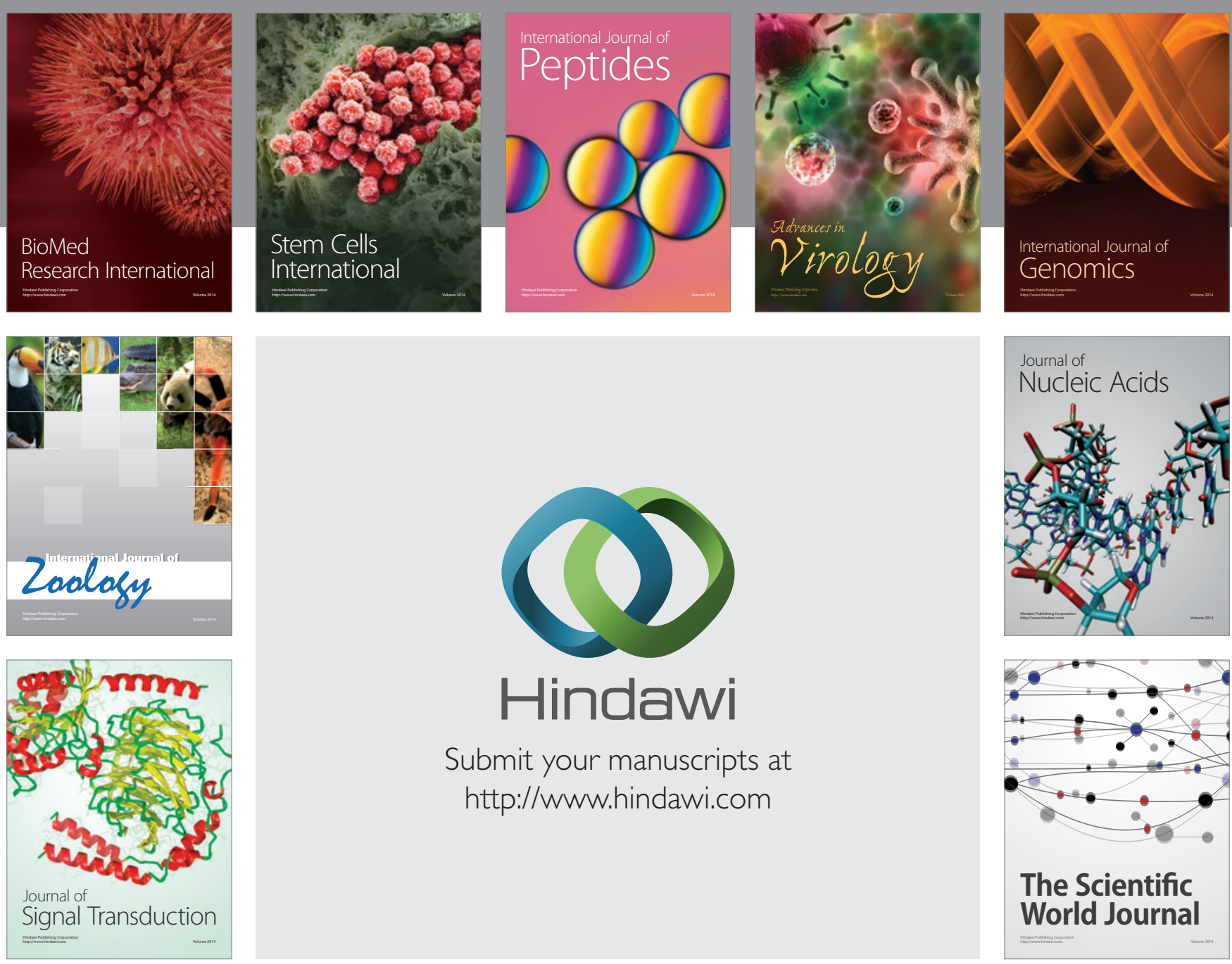

Submit your manuscripts at

http://www.hindawi.com
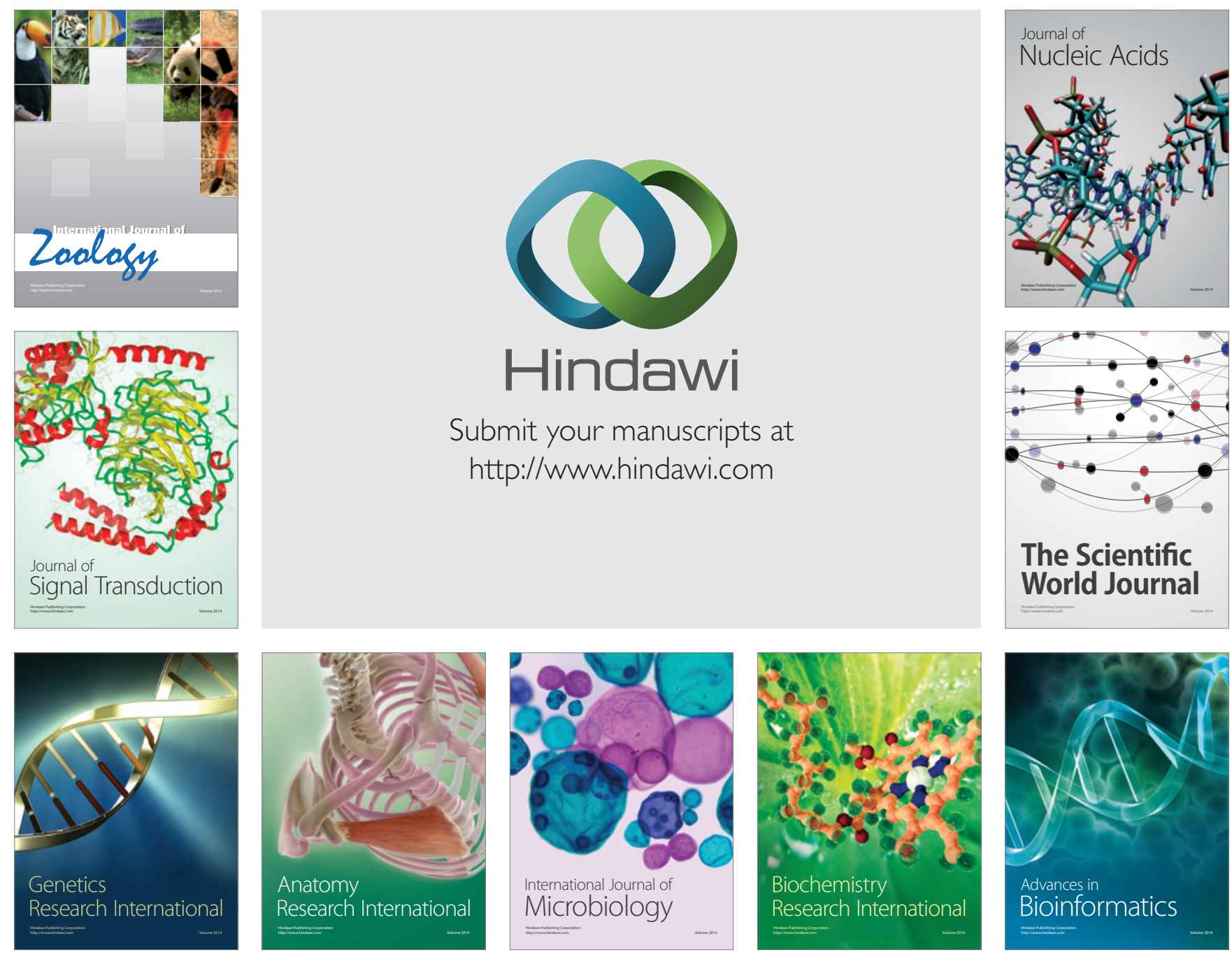

The Scientific World Journal
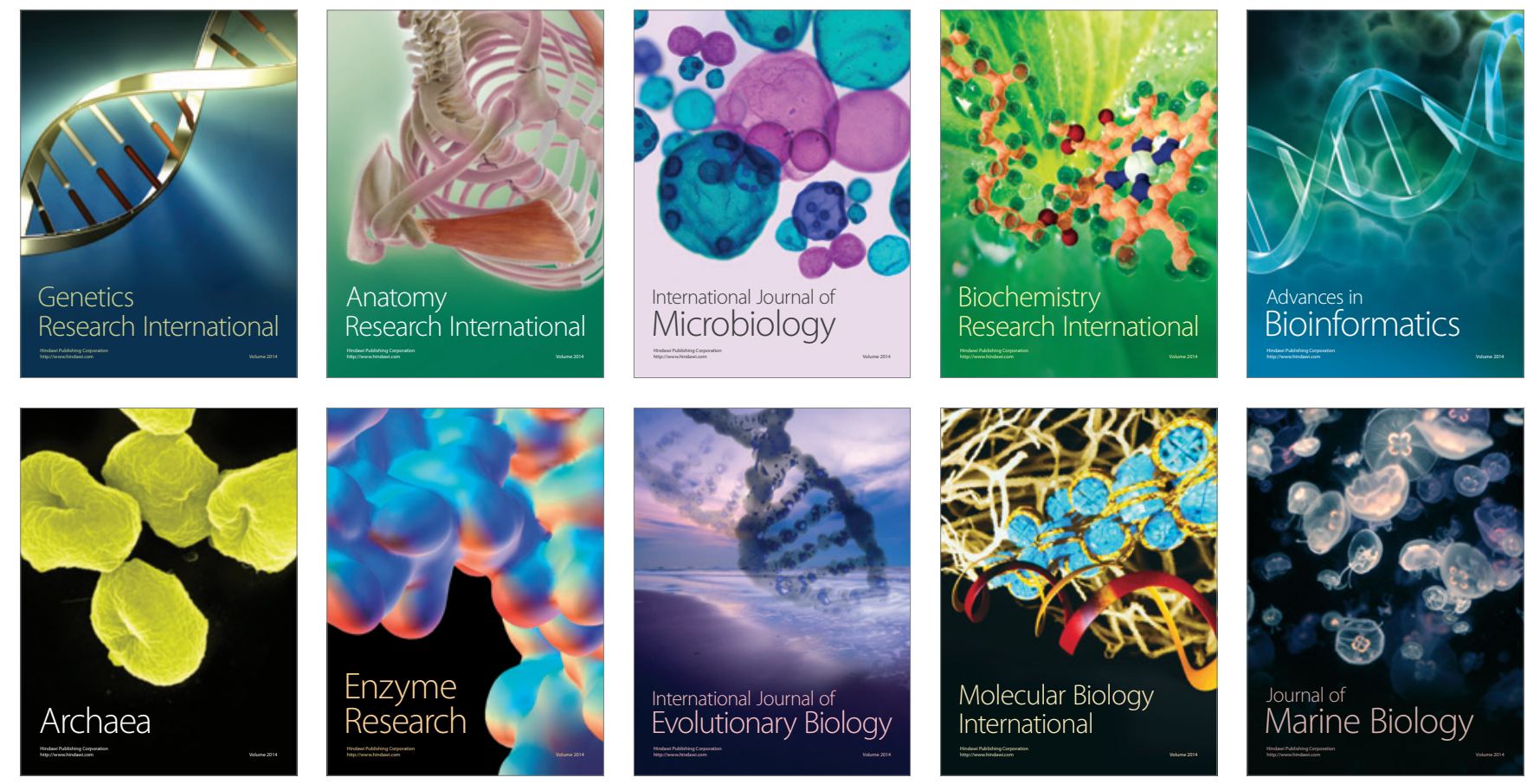